\title{
Die Pflegezeitschrift - jetzt online lesen
}

\begin{abstract}
Was Sie gerade auf Papier gedruckt in den Händen halten, können Sie auch online auf Ihrem Smartphone, Tablet oder Computer lesen. Ab sofort gibt es die Pflegezeitschrift auf SpringerPflege. de, dem neuen Portal von Springer. Abonnenten der Print-Ausgabe erhalten kostenlos Zugriff auf alle Ausgaben ab April 2017.
\end{abstract}

") Die Pflegezeitschrift finden Sie über eine eigene Startseite auf SpringerPflege.de. Dort sind alle Inhalte und Informationen zur Zeitschrift verlinkt. Sie erreichen die Startseite zum Beispiel über den Menüpunkt „Zeitschriften“ oder direkt über www.springerpflege. de/pflegezeitschrift/12197620. Dort angekommen können Sie über das Archiv auf die Ausgaben zugreifen, die seit der Übernahme der Pflegezeitschrift durch Springer Pflege erschie- nen sind. Zudem können Sie dort ältere Print-Ausgaben (bis Heft 1/2015) nachbestellen.

\section{Portabel und kostenlos}

Die aktuellen Ausgaben der Pflegezeitschrift ab Heft 4/2017 können Sie auch digital im gewohnten Magazinlayout als ePaper lesen. Dieses bietet neben einer Suchmaske auch ein interaktives Inhaltsverzeichnis, sodass Sie schnell zum gewünschten Beitrag gelangen. Zoomfunktion und Seitenübersicht erleichtern das Lesen und die Navigation durch die Ausgabe. Das ePaper wurde für die Tabletnutzung optimiert, sodass Sie unkompliziert mit dem Finger durch die Magazinseiten „blättern“ können. Außerdem gibt es eine Download-Funktion, mit deren Hilfe Sie die Pflegezeitschrift überallhin mitnehmen und offline lesen können. Die Ergänzung unserer Printausgabe durch diese digitalen Tools lässt Sie Ihre Lesezeit individuell einteilen und optimal nutzen.

Der Zugang zu unseren Beiträgen und zum ePaper ist für Abonnenten der Pflegezeitschrift kostenlos. Es ist allerdings eine Registrierung auf SpringerPflege.de erforderlich.

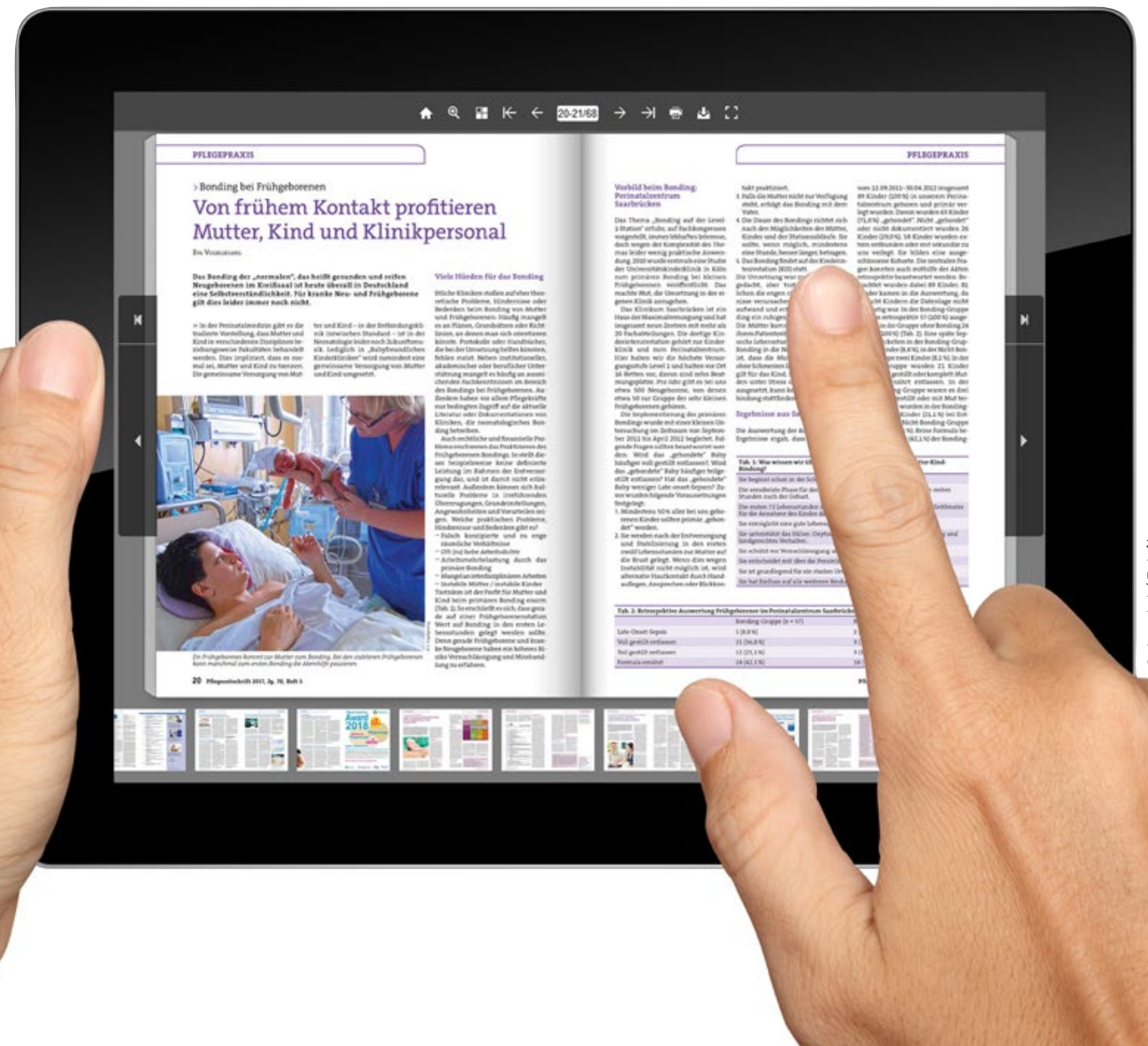

Kommen Sie nicht weiter?

Bei Fragen und Problemen rund um das Portal SpringerPflege.de hilft Ihnen unser Kundenservice weiter. Bitte schicken Sie eine E-Mail an kundenservice@springerpflege.de oder wählen Sie 08007780777. 